\title{
Lo imposible como práctica de clase: Darío-Martí
}

Mario Roberto Morales

University of Northern Iowa

Estados Unidos

\section{La estructura de la imposibilidad}

$\mathbf{E}$ 1 paso del siglo XIX al XX sorprende a Centroamérica en una encrucijada que, como parte consubstancial de ese tránsito, habría de marcar el desarrollo de su peculiar modernidad. A excepción de Costa Rica -y con Guatemala como contrapartida de aquella y prototipo quizás del modelo- el área se desarrollaba según los cauces trazados por un largo pasado colonial que había originado una estructura de tenencia de la tierra derivada de las necesidades económicas españolas después de la Conquista, y que había determinado, entre otros factores, un tremendo arraigo de los conquistadores al territorio a partir de su conversión en terratenientes (encomenderos) según principios de señorío; esta medida se desarrollaría a lo largo de la Colonia hasta llegarse a consolidar una clase terrateniente semifeudal criolla que se apropia del poder político a partir de la independencia de España en 1821 y que - dada la incapacidad del régimen colonial en cuanto a dejar consolidadas ciertas bases para el desarrollo de una relativa autonomía económica del área (en tanto siempre basó la realización del producto expoliado en el monopolio comercial metropolitano)necesariamente recorre el históricamente señalado camino de prolongar las estructuras coloniales hasta la revolución liberal de 1871 operada en Guatemala. Todo esto en lo que se refiere al antecedente necesario. En cuanto al proceso que se inicia en 1871, este constituye el elemento clave de la encrucijada centroamericana del entresiglo puesto que, sobre la base de contradicciones coloniales en el desarrollo como la interdiscriminación indio-ladino $\mathrm{y}$, en general, sobre la base de la contradicción terrateniente criollo-siervo colonial, en Guatemala se inicia un proceso de acumulación originaria de capital que vendrá a crear, en el plan de la apología, ciertas -llamémoslas así- expectativas de imposibilidad en la mentalidad colonizada y colonizante de la clase en el poder y en la de las capas por ella influenciadas. Las bases para iniciar medidas de acumulación originaria se habían comenzado a echar desde antes; en El Salvador -que junto a Guatemala fue un país en el que este proceso se profundizó hasta modificar la matriz colonial por medio del desarrollo capitalista-, 
el año 1864 marca el inicio embrionario de este fenómeno. Entonces las expectativas ideológicas de imposibilidad de fondo se encuentran en el hecho histórico de que el capitalismo en Centroamérica era un fenómeno condenado necesariamente a no llegar a convertirse en un proyecto autónomo $\mathrm{y}$ verdaderamente nacional-burgués $\mathrm{y}$, con todo-adelante dilucidaremos el porqué-, la apropiación ideológica de los principios de la democracia burguesa vendrá a transformarse en el desarrollo de pertinaces frustraciones colectivas -aunque se trate de una colectividad de élites- que pronto se convertirá en un alienado sentido de incompletitud ontológica que, además, como es natural, buscará expresión estética a fin de embellecer e institucionalizar la desesperación existencial, cuestión que logra sonoramente en la concreción literaria del autismo poético-formal del Rubén Darío de $A z u l$ y Prosas profanas principalmente o -y para continuar con el caso guatemalteco- en la práctica personalista, desarraigante y renegada de un Enrique Gómez Carrillo, prototipo centroamericano del escritor comprometido con su propia vergüenza ontológica y prácticamente obsesivo, por lo mismo, de la escritura del vacío burilado y de la concepción estatista de la vida; todo ello, naturalmente, bajo la sombra fantasmal -a veces negada-de Darío.

Pero vayamos explicando la estructura de la imposibilidad centroamericana. Las medidas de acumulación originaria que se operan en Guatemala son el resultado de la satisfacción de necesidades concretas del mercado mundial, que es el mecanismo imprescindible del capitalismo para internacionalizar a escala planetaria el sistema e ingresar paulatinamente en su última fase de desarrollo. En aquel momento, el mercado mundial capitalista necesitaba adquirir café en grandes cantidades puesto que la cafeína es una droga que estimula la circulación sanguínea y elimina momentáneamente la sensación de cansancio, y esto determinaba su enorme demanda en Europa, en donde el paso de la extracción de plusvalía absoluta a la extracción de plusvalía relativa se operaba lentamente y la sobreexplotación de la fuerza de trabajo garantizaba que la revolución industrial caminara a todo vapor. En el plano interno, el cultivo del café en la cantidad necesaria al mercado mundial, implicaba una reconcentración de la tierra, para lo cual era necesario implementar las medidas previas para el inicio de una acumulación originaria, tales como la expropiación de terrenos comunales y eclesiásticos y la puesta en subasta de las tierras que, dada la matriz colonial precedente, sólo podían ser adquiridas por la clase terrateniente constituida. Se creaban con estas medidas las condiciones de existencia de un conglomerado de trabajadores liberados de las ataduras de la propiedad sobre las condiciones de su reproducción y que solamente tenían fuerza de trabajo para ser vendida. Las bases para el desarrollo de una conformación clasista diferente de la colonial quedaban igualmente echadas. Pero la imposibilidad estructural de un desarrollo capitalista fluido -en tanto que las economías locales debían encajar en el mosaico de necesidades imperialistas según la división internacional del trabajo- determinará que la clase dominante se constituya en un pequeño conglomerado de aspiraciones burguesas y nostalgias feudales, de espiritualidad pragmática y práctica señorial asentada en la servidumbre, de cinismo y 
compostura nobiliaria, de indefinición, de duda, de imitación caricaturesca y deformada, como que deformación es ya la mera imitación. Más de veinte años después, el proceso se inicia en Nicaragua pero no con perfiles tan nítidos como en Guatemala, cuestión que hace de la imposibilidad -estructural e ideológica- un sueño todavía más amargo puesto que el proceso liberal tardío de Nicaragua es frenado por el imperialismo norteamericano a fin de conseguir la concesión para construir el famoso canal interoceánico: José Santos Zelaya es derrocado en 1909 (habiendo asumido en 1893) y sale al exilio en donde es asistido por Darío, cuya inspiración se había visto motivada por la descarada injerencia norteamericana en su país y había publicado encendidas prosas políticas.

Vayamos, pues, desarrollando las causas de la imposibilidad. La vía capitalista de desarrollo estaba definida de antemano; no se habría de desarrollar una industria nacional, no se habría de proletarizar plenamente la mano de obra sino, por el contrario, se habría de recrudecer la servidumbre, y la forma de dominación política que viabilizara tal desarrollo necesariamente de trabajo. La vía sería terrateniente, latifundista, atrasada, de grandes costos sociales y políticos. La lentitud y tortuosidad del proceso de proletarización de las masas del campo iría conformando y amasando la ideología de la expectativa de imposibilidad en el plano de sus impuestas aspiraciones pequeño-burguesas y en el de la conciencia de las capas medias surgidas a lo largo de las primeras tres y cuatro décadas del siglo $\mathrm{XX}$, las cuales conformarían una exacerbada ideología de la imitación que oscilará entre el desplante señorial terrateniente y la compostura refinada y urbana del industrial y el comerciante, aspectos ambos de imposibilidades rotundas para estos estratos sociales y más bien aproximaciones ilusorias en el marco de la dominación de una oligarquía terrateniente que habría de evolucionar, en virtud de su involucramiento en diversas formas de acumulación capitalista, hasta fundirse modernamente con el capital monopolista transnacional, absorbiendo a la casta militar y transformándola en parte integrante de la oligarquía capitalista, como ha ocurrido en Guatemala. En Costa Rica, en donde la ausencia de un pasado colonial y de una masa nativa impidió una concentración latifundista de la tierra, la democracia burguesa se instituyó otorgando al país un desarrollo económico exento del terror gubernamental pero a la vez deformó - al transfigurar la lucha de clases en lucha permanente por la democracia burguesa- el desarrollo de elementos de identidad nacional auténticos, a tal extremo que la ideología de la imitación constituye hoy día -en relación con la moda consumista norteamericana en todos los planos- el rasgo nacional de cultura cotidianamente observable en su burguesía, en sus extensas y mediatizadas capas medias y en su intelectualidad en buena parte aburguesada.

El siglo XX había arribado, pues, a nuestras costas, trayendo además la nueva de los contratos bananeros que, como enclaves, habrían de continuar la obra de infraestructura iniciada por las necesidades de transportación del café, como los ferrocarriles, y habrían de reforzar también las dictaduras con presiones políticas y militares a fin de viabilizar e institucionalizar la explotación y represión de un proletariado combativo que se había ido 
formando a los lados de las vías férreas, en las tierras cedidas por las dictaduras a las compañías bananeras.

Esta es la realidad centroamericana hasta 1929, año de la crisis capitalista mundial: la conformación económico-social local del capitalismo pero en el marco de las necesidades de su fase imperialista de desarrollo internacional, cuestión que definía de antemano nuestros capitalismos como dependientes y oligárquicos (es decir imposibilitados de seguir un rumbo siquiera parecido al de las potencias imperiales, precisamente porque para que ellas acusaran tal desarrollo se hacía necesario el subdesarrollo nuestro), consolidando y desarrollando, mediante esta base económica, la matriz estructural de una ideología de la imitación y de la renegación de "lo propio" (que se resumía en una realidad de explotación y opresión), la cual -como fenómeno gestado en la Conquista y consolidado durante la Colonia- hallaba en el capitalismo cauces adecuados para su doloroso desarrollo.

\section{La ideología de la imposibilidad}

La gestación de cierta conciencia escindida con contenidos esenciales contradictorios, y que mantiene al centroamericano oscilando entre la apropiación de su pasado histórico y la renegación vergonzante de este (entre el orgullo y la vergüenza), arranca de la conquista española en tanto el hecho histórico que sienta las bases para semejante conformación mental y moral por medio del entronizamiento de la histórica superioridad del conquistador, se apoya sobre el poder económico y político español. Este poder había colocado en la base de la pirámide social a la población natural, dando origen así a la identificación de los criterios de explotación e inferioridad racial, personificados en el indio sojuzgado y practicante de una moralidad que correspondía a un estado social en el que la competencia individualista no constituía aún el motor de la acción humana, como era el caso de la ideología de los españoles.

Estos son los componentes de la matriz social que echará al mundo a la población mestiza de Nuestra América y que marcan el elemento básico de su ideología torturada, dividida, dual, amante y renegadora de lo suyo, deslumbrada por el brillo de la mercancía y atraído atávicamente por el embrujo y el esplendor de las pirámides; obligada externamente a optar.

La conciencia escindida se consolida, como sustrato enajenado mestizo, durante la colonización, a partir de la bestialización del indio - ente social creado por ella- y de la necesaria bestialización del bestializador quien, en su lucha criolla de apoderarse del territorio, de sus fuerzas productivas, instrumentaliza a las de macehuales amotinados para protagonizar la independencia de España. Después, la conciencia escindida sufre un "desarrollo" (las comillas obedecen a la necesidad de puntualizar el carácter enajenado de tal desarrollo) con la implantación del Estado Nacional oligárgico; es decir, con la implantación de la vía terrateniente de desarrollo capitalista, dadas las necesidades determinantes de la división internacional del trabajo. Esta realidad estructural se expresa, en el plano de la ideología, mediante de una mentalidad señorial terrateniente de hondas nostalgias 
feudales, por un lado, $\mathrm{y}$, por otro, mediante de la incubación de sueños de desarrollo industrial con todo y las desventuras existenciales urbanas que en las metrópolis capitalistas eso conllevaba.

En el plano estructural, nada de esto era plena (es decir), históricamente posible, y entonces la conciencia escindida busca cauces propios de su expresión que alcanzan oficialización y consagración locales e incluso universales. Tal es el caso de Rubén Darío, quien además busca en la historia local la reivindicación añorada.

También se desarrollan expresiones de esta conciencia escindida que se rebasan a sí mismas, desbordando sus condicionantes político-culturales liberales-románticos, y que desembocan con vigor en una concepción americanista de hondas raíces fincadas en la historia del continente, sobre todo en la de su pasado precolombino. Tal es el caso de la obra y el ejemplo de José Martí, con quien se unen la americanidad y el americanismo, fundidos en una ética imposibilidad impuesta, esta vez extendida a toda América Latina y el Caribe, a toda Nuestra América.

La americanidad -como visión unificadora y rescatadora de la cultura de los vencidos y los explotados para su apropiación popular contemporánea- constituye una concepción a una práctica de vanguardia, y es en relación con este criterio que debemos estudiar a Darío y a Martí, como unidad y binomio seminal para la cultura de Nuestra América, puesto que ambos buscaron en ella -cada uno según su capacidad y de acuerdo con sus necesidades- las claves de la superación de lo imposible. Todo, naturalmente, bajo el criterio histórico de considerarlos como hombres de su época y partícipes necesarios, ambos, de la cultura dominante. Ello plantea la necesidad de una consideración total y globalizante de su actividad; es decir, su consideración como hombres totales y actuantes, y no solamente como literatos o políticos, so pena de minimizar su significado. En tanto que hombres fueron, y totales y contradictorios, la contradicción se impone como el punto de partida para esclarecérnoslos, quedando con ello fuera de óptica la posibilidad de condenarlos o glorificarlos como resultado de nuestra apropiación, que debe necesariamente ser objetiva en tanto necesidad histórica. Esta postura de ninguna manera busca caer en la deplorable actitud de la conciliación gratuita. Al contrario, si se vislumbran sus resultados a largo plazo, se trueca en un difícil compromiso para con ambos y para con los intereses de la revolución en América Central y en toda Nuestra América.

Si admitimos que la escritura de textos literarios constituye una práctica ideológica de clase (una conducta), hubimos de definir históricamente la ideología dual de la clase a la que pertenecen sus practicantes -en especial a los que nos interesa clarificar- a fin de podernos explicar sus posibilidades históricas y concretas de desarrollo intelectual e ideológico, así como la diversidad igualmente ideológica que pueden presentar sus obras, riquísimas en lo formal y en lo contenidístico, a lo largo de sus vidas y de su práctica literaria. Ni Darío ni Martí escapan a semejante consideración, y el eje metodológico para enjuiciarlos globalmente debe ser el de arrancar de la contradicción ideológica 
gestada por la confluencia de posibilidades e imposibilidades de una formación social dependiente, pero capitalista al fin y al cabo. Sui géneris situación habrá de dar origen a una expresión sui géneris, conformadora de una tradición de cultura que tiene desarrollos contemporáneos en todos los géneros literarios en el mundo, necesarios de ser elucidados. Íntimamente ligado a este problema propio de la cultura dominante, se encuentra el de la necesaria consideración del desarrollo o involución de las culturas populares y su absorción por el capitalismo, o el de la producción de la subcultura de masas fabricada por el aparato de poder para el consumo mercantilizado y reproducción ideológica masificada de los pseudovalores dominantes. Desgraciadamente y por razones obvias, estos problemas no los trataremos aquí.

\section{Martí o la práctica de lo imposible por medio del amor}

El filón humano que para la cultura y la economía dominantes aparece como subterráneo, y que para Martí constituye foco de redención de América y de la Humanidad, hay que buscarlo en el desarrollo de las civilizaciones precolombinas, en las cuales, de la matriz de la comunidad primitiva, que implicó una identificación total del hombre con las condiciones de su reproducción, y por tanto, fundó una ideología que no dualizaba la perfección espiritual y la acción sobre el mundo, se desarrolló una forma social de transición que implicaba ya un proceso de alejamiento del hombre respecto de sus condiciones básicas de reproducción: la sociedad despótico-tributaria, que -en el marco histórico de las sociedades clasistas- implicó también una época de equilibrio entre los factores de explotación y, por lo tanto, en vista de que el divorcio del hombre y sus condiciones vitales no era completo ni aún avanzado, permitió el desarrollo de esta ideología, sintetizada en la obra del hombre que a partir del cultivo de sus virtudes asciende a la categoría de divinidad y que las culturas de Mesoamérica conocen como la imagen de la síntesis contradictoria expresada en Kukulkan, la Serpiente Emplumada. Martí ve, en el indio, no sólo la encarnación de esta redención necesaria ya a la altura del desarrollo capitalista dependiente que le tocó vivir, sino también un sujeto real revolucionario, imprescindible para la liberación de todas las clases y todas las etnias de Nuestra América, en tanto vio con claridad meridiana el papel productivo del indio en el concierto económico de su época. Martí asume la filosofía de la totalidad e identidad Hombre-Mundo, Materia-Conciencia como una práctica moral inserta con decisión en su tiempo y, consecuentemente, muere en combate.

Es claro que la forma de la colosal expresión martiana estuvo pautada -en sus años formativos- por el liberalismo y por las corrientes literarias románticas, pero se trata de pautas ampliamente desbordadas por la vitalidad y el genio del hombre Martí, del ente humano total Martí.

El capitalismo, que implica el grado más alto de separación del hombre respecto de las condiciones de su reproducción, impactaba a Martí, -porque lo concebía justamente como el gran obstáculo para la realización de la fusión hombre-mundo- no sólo en su versión latinoamericana dependiente, sino también en la pujanza 
económica de Norteamérica, destinada por las leyes de ese desarrollo a absorver las economías latinoamericanas. Y él no se plantea frente a ello un lamento ni un alejamiento ni un refugio artepurista, sino se plantea una acción, la cual -para él- era sólo posible una vez esclarecido -y esto lo postula como ley humana- el propio yo como lugar de dación de sí mismo y del mundo; como ente autoontocreador.

El alma de Darío es doblemente torturada porque no arriba a este logro interno y su desborde emana de esa fractura interior de su conciencia, de donde su americanismo más ligado a la circunstancia vital y a veces contradicho por escritos y acciones que no rebasaban preocupaciones inmediatas ligadas a la sobrevivencia y a la satisfacción de instintos desbordados de bohemia irredenta.

La hazaña de Darío hay que buscarla, sin embargo, en su proceso estético-literario, como expresión que este es de una época de grandes cambios ya definida en sus elementos esenciales, puesto que constituye un claro ejemplo de la dialéctica que va de la enajenación al descubrimiento de caminos desalienadores a partir de una práctica ideológico-técnica literaria de clases, que dota a Latinoamérica y al mundo de un instrumento nuevo, adecuado a las necesidades expresivas de una realidad contundente que ya se había entronizado en el planeta. Intuye también el peligro norteamericano hacia nuestras pequeñas repúblicas y bucea en las profundidades de nuestros orígenes, sólo que sin el arma espiritual de Martí: su concepción del amor como fuerza omnímoda universal. Bucea sí, aunque sin trascender el conocimiento que otorga la lectura a un alma torturada por sus propias debilidades. Con todo, evidenciando un vigor indomable, Darío se funda como el fenómeno Darío para nuestra historia y nuestra cultura, y se propone como cultor continental, siempre dentro de la práctica ideológica posible en el ámbito clasista dominante, al igual que Martí, quien también produce en el mismo ámbito sólo que superándolo ideológicamente.

La concepción y práctica martianas se desarrollan y concretan contemporáneamente, en el plano del movimiento de las masas, en las luchas populares del continente y en la revolución cubana como clima irradiador de americanidad libertaria, de práctica revolucionaria y de redención humana.

El caso de Darío ha corrido una suerte diferente hasta ahora puesto que ha sufrido una apropiación instrumentalizada por el somocismo y por las clases dominantes en el capitalismo mundial, al rescatar de él en forma apotéotica solamente los cantos de sirena y el autismo de mármol y joyería. Nada más que un fenómeno -pensamosde auténtica inspiración martiana, como la revolución sandinista, puede rescatar a Darío de las maltrechas garras de la vieja historia oficial oligarca, no para instituirlo como el paradigma de conducta consecuente que no fue, sino como el hombre síntesis que se echa a cuestas la contradicción estructural de su tierra centroamericana y de su época y que, aún en medio de conmiseración y abjuración provincianas, busca desesperadamente la tabla salvadora que cree encontrar en una concepción y práctica esteticistas de la vida y de la literatura, porque con todo, logra instaurar una renovación revolucionaria de la lengua y 
de la literatura y abre caminos que continúan siendo ampliados por la cultura latinoamericana y mundial hoy día.

Si nosotros revisamos lo que la estadía de Martí y Darío en Guatemala trocó en producción escritural, notaremos estas diferencias entre ambos y también su carácter fundamental para el posterior desarrollo de la cultura y de la lucha liberadora en Centroamérica. Ambos vivieron en Guatemala, durante su primera estadía, cuando tenían 25 años y la diferencia con la que arriban es de 13 años aproximadamente. Martí escribe algunas cartas en las que se refleja ya su vocación apostólica y al mismo tiempo celebra las medidas de acumulación originaria, el cultivo del banano, los árboles de quina y la diversificación de cultivos durante el mandato de Barrios. Darío llega cuando la dictadura liberal se ha consolidado y el primer escrito suyo -referente al golpe de Ezeta en El Salvador- se escribe y publica por órdenes que personalmente le da el presidente Barillas. Martí deja Guatemala por fidelidad a sus principios y Darío permanece tratando infructuosamente de lograr el favor gubernamental hasta su partida hacia Costa Rica. Adhesión, sí, la de ambos, al liberalismo, cada uno según se lo dicta su personal práctica ideológica. Martí evolucionará hasta abrazar el antimperialismo conciente y el otro llegará a la indignación sincera, sí, y antimperialista en sus connotaciones, pero más espontánea y producto de la determinación de condicionantes materiales que de la reflexión profunda característica de Martí.

Cuando hablamos de práctica ideológica nos referimos a actos comprometidos con una realidad. En ese sentido, la práctica literaria, así definida, sólo se explica en tanto acto comprometido; acto que, por otra parte, constituye un hecho entre varios que conforman una conducta ideológica total. La práctica literaria como práctica de clase se explica solo en tanto elemento integrador de una conducta clasista global que puede ser contradictoria en sus manifestaciones de la determinancia que sobre ella tienen las condiciones objetivas de reproducción del hombre que la protagoniza y ejerce comprometidamente, ya sea este compromiso voluntario o no, conciente o no conciente.

Que el lenguaje y el pensamiento son dos elementos constitutivos de un solo proceso, el proceso de conocimiento producto de la praxis o contacto ontocreador del hombre con el mundo, es cosa que se sabe. La escritura y la literatura, en tanto ejercicios formales que expresan procesos cognoscitivos en sus resultados, siempre constituyen vehículos de comunicación de actos ideológicos de clase y su elaboración constituye práctica ideológica clasista en tanto actos comprometidos con la sociedad.

La ideología en general es siempre la forma ideal, intuitiva, como los hombres expresan (justificándolas o cuestionándolas) las condiciones generales y particulares de la reproducción de su existencia $\mathrm{y}$, en ese sentido, la ideología es, por necesidad, clasistamente condicionada.

Hemos juzgado necesario hacer esta digresión puesto que si hemos de juzgar a Dario y Martí, si hemos de ubicarlos en su significado para la cultura en desarrollo de Nuestra América, ello tendrá que hacerse primeramente según consideración como sujetos actuantes, globales, sin especialización, aun cuando el primero soñara y hasta lograra la 
consagración oficiosa de vate, porque son sus actos de hombres los que pueden permitirnos semejante ubicación, de lo contrario corremos el riesgo de falsearlos.

Tanto uno como el otro realizaron una obra enorme para nuestra cultura (acto también). Uno, habiendo encontrado en el amor la piedra de toque de todas las cosas, y el otro buscándolo con desesperación a menudo por senderos tortuosos y dolientes. Ambos, en todo caso, hijos y padres de la ideología liberadora de la América Nuestra, cuyas raíces se encuentran en aquellas sociedades no divorciadas del mundo a las que habremos de volver sobre bases cualitativamente nuevas, como lo vislumbró Martí, mediante la práctica revolucionaria de la erradicación de las condiciones de reproducción del odio humano.

\section{Darío o la pose de lo imposible como práctica de clase de la imposibilidad}

Ya no cabe la menor duda de que Darío fue un hombre enterado -y muy bien enterado, como que su informante a menudo era el mimo José Santos Zelaya-del acontecer político de su tiempo. Se sabe igualmente que fue un activo escritor político directamente comprometido con el liberalismo de su país y colaborador en tareas políticas dentro y fuera de Nicaragua, desde su juventud hasta ya muy cercana su muerte. El liberalismo centroamericano - esbozado antes- era secreto en ese terreno; credo al que, por otro lado, jamás subordinó su autoconcepción de la condición de poeta; Darío operó más bien la fórmula contraria, dando lugar con ello a que se le apropiara como cantor de etéreas realidades, en el ámbito municipal de las "culturas nacionales" de nuestras repúblicas, torturadas por la vía terrateniente de desarrollo capitalista y la ideología de la imposibilidad y la frustración pequeñoburguesa que el muro estructural imponía al sueño americano en Centroamérica; sueño que, por otro lado, recorría una etapa cavernaria con el gran garrote asido, hacía la consecución de sustitutos para arma tan rudimentaria. Darío fue, efectivamente, el principal constructor de su imagen de poeta etéreo $\mathrm{y}$, por tanto, la apropiación histórica que inicialmente se hace de él es una apropiación consecuente con el tipo de promoción y con el producto promovido.

El desarraigo cantado, la renuncia explícita y disciplicente del terruño (aunque luego largamente lo añore y lo cante) y de la cultura local carente de tradición, y el cosmopolitismo frívolo y superficial constituyeron -sí- los elementos de la pose dariana que muy a su holgura lo ayudan a cumplir la función de contradecir -con un lenguaje de plumas, terciopelo y metales-a una oligarquía enfrentada a las posibilidades del progreso liberal o al estatismo semifeudalizante en relación con economías campesinas de organización precolombina.

El yoísmo dariano es expresión ideológicoindividual de progreso liberal, de resistencia actuante contra el conservadurismo reaccionario oligárgico que quería guarecerse a la sombra de empolvados blasones españoles. A la contradicción estructural y a las imposibilidades convertidas en asunto esencial con la instauración de la vía Junker, Darío da una respuesta individualista de rebeldía -la bohemia sostenida, la sensualidad como punto de vista y la militancia del ensueño como sentido de la existencia- enderezada en lo inmediato contra la vulgaridad, la 
chabacanería y la ausencia -en suma- de una tradición cultural noble y respetable, por la cual sentía una nostalgia de siempre (conciencia escindida), una añoranza fundamental. Y el individualismo dariano se convierte en poética mantenida hasta en su madurez, pues - cuando escribe (en la nota al lector de Cantos de Vida y Esperanza): "Mañana podremos ser yanquis (y es lo más probable); de todas maneras, mi protesta queda escrita sobre las alas de los inmaculados cisnes, tan ilustrados como Júpiter". Darío está sustentando -avalada por una larga práctica ideológico-literaria amparada por protectorados liberales de altos vuelos presidenciales centroamericanos- una propuesta estética acerca de la obligación del escritor latinoamericano (conciencia escindida) de ser original en su temática americana pero implícita una altísima calidad formal (que no tendría otro parangón que la tradicción cultural de Occidente, con decorativas y vistosas pinceladas orientales de ambientación). Es increíble que con tan endeble mezcla ideológica, haya podido construir tan rotundo edificio formal.

Por otro lado, Darío funda con su práctica una tradición en el terreno de la autoconcepción del poeta centroamericano como ser excelso y exento de compromisos sociales más estrechos y que no necesariamente pasen por la impresión de libros, las glorias municipales y los juegos florales; cuántos poetas nuestros -anhelantes tras las alambradas de las expectativas de imposibilidad- publican sus opúsculos con sus salarios de tinterillos o maestros de escuela y se rehúsan a empuñar las armas o a ganar la calle por reivindicaciones gremiales so pretexto de una abstracta e ilusoria condición de vate que tiene su antecedente local y sonoro en Darío. He aquí algunos de los resultados de la apropiación oligárquica de Darío, a la que él mismo contribuyó como principal y lúcido promotor.

Por muy explicable que la torre de marfil pueda tornarse en su relación histórica con el desarrollo económico, aun la personalidad de Darío como esteta parasitariamente autoconcebido, y buscador de mecenazgos que sabe hallar en los ambientes oropelados del liberalismo y, en fin, como individualidad responsable, pareciera quedar irredenta al menos a estas alturas de la investigación dariana en Nicaragua.

La nueva apropiación de Darío, que solo la revolución sandinista puede operar por medio de sus intelectuales, se reclama como una apropiación objetivo, mesurada y serena, nunca teñida de resabios transfigurados de la ideología de las expectativas de imposibilidad que se entronizó en Centroamérica y que, particularmente en Nicaragua, cobró formas exacerbadas de desarrollo con la dictadura somocista, las cuales se expresan en innumerables rasgos de enajenación ideológica colectiva que hoy enfrenta como problema complejo heredado de la vieja cualidad, precisamente la revolución sandinista.

Y es que si Darío escribió para Barillas al llegar a Guatemala por primera vez siendo muy joven; si escribió para Estrada Cabrera - contra su voluntad-siendo ya maduro, al llegar a Guatemala por última vez, resulta muy del caso preguntarse si su amistad y colaboración con Zelaya y sus escritos contra los Estados Unidos no hayan estado enmarcados dentro de una misma concepción de moralidad francamente oportunista - no tiene otro nombre-, soñadora, estetizante 
y ególatra, y que en fin de cuentas selló su apropiación oligárquica como poeta etéreo. ¿Qué fue Darío al fin? Creemos que no se trata de una disyuntiva, de una opción entre posiciones irreconciliables. Se impone como tarea de todos nosotros contribuir a ir fijando la figura de un Darío total, de un Darío-hombre-con-una-práctica-ideológico-literaria-de-clase, que nos legó un patrimonio de desarrollos actuales en Centroamérica y el mundo ya indiscutible. Sería, por ejemplo, difícil interpretar el desarrollo de la literatura guatemalteca sin el punto de remitencia dariano y -para reincorporarlo al discurso- martiano. Porque cuando se echa un vistazo hacia atrás y se evoca la obra -ética, cincelada y desbordante- de Rafael Arévalo Martínez; el equilibrio obsesivo en forma y contenido de la práctica literaria de César Brañas; el conceptualismo rígida y ricamente expresado de Luis Cardoza y Aragón; la explosión asturiana; el ruralismo colorido de Flavio Herrera, y aun la compulsión formal con la que se expresa una ideología torturada en las novelas de Marco Antonio Flores y Arturo Arias, uno no puede menos que adivinar un sendero trazado por los paradigmas de cultura iniciados por Martí y Darío, cuestión esta que abre una brecha a la investigación literaria en Guatemala, necesaria de ser ampliada.

\section{La médula humana como piedra de toque de la nueva apropiación}

La actividad de Darío no puede reducirse a haber tratado de aclimatar la cultura francesa - su modelo- a las circunstancias geográficas de su existencia centroamericana, aunque el juicio sí señala un rasgo esencial del cultor. Podría decirse -y se ha dicho- que lo que Darío logra expresar -talvez a pesar suyo y valiéndose de bagajes culturales que percibía como la negación de lo que en su país se le ofrecía como imposible- es la vía del capitalismo asignada a Centroamérica, sus contradicciones transformadas en efectos ideológicos tortuosos, sobre todo en sectores sociales parasitarios, no productores de mercancías. El Modernismo vendría a ser -al menos en una de sus vertientes, quizá la esencial- expresión de la apropiación imitativa de los conflictos existenciales del mundo occidental que sí podía y debió transitar fluidamente el camino del capitalismo. Barnices nostálgicos de imposibilidades estructurales, los rasgos ideológicos modernistas centroamericanos tienen naturalmente hoy día un terreno abonado en el cual reproducirse a discreción aunque cada vez más lánguidamente en razón del despertar político de las masas y sus acciones. Pero la concepción del arte como una práctica ególatra que debe ir bien envuelta según los requerimientos del mercado, se desarrolla vigorosamente en Nuestra América y lo seguirá haciendo por mucho tiempo todavía, conectada -apreciamos- directamente con el fenómeno modernista y con el fenómeno Darío, enmarcados en el capitalismo.

Algo que debemos tener en cuenta al juzgar a Darío es el hecho que la ideología político-social del artista no corresponde necesariamente a la expresada en una o varias de sus obras. ¿Por qué? Porque la factura de una obra depende en mucho de las circunstancias que envuelven la práctica artística, que es históricamente condicionada. Es imprescindible, pues, analizar las circunstancias inmediatas de la práctica política y literaria de Darío y no solamente partir de 
escritos de tema político o versos dirigidos a un presidente norteamericano, para proclamarlo ideológicamente como algo.

Ubicar a Darío en su circunstancia según el método científico es una tarea de los trabajadores de la cultura centroamericanos y del mundo necesitados de hallar los vínculos históricos entre su pasado y su futuro. Esta tarea fue señalada por Carlos Fonseca al escribir "surgido Rubén Darío en la transición del siglo XIX al XX, etapa de ascenso histórico en Nicaragua, la médula humana y latinoamericanista de su obra vendrá a ser rescatada en el esencial ascenso que vive su Nicaragua, no dispuesta a quedarse atrás en la marcha de los pueblos hacia un destino libre." Fonseca habla de "rescatar la médula humana" y luego añade "y latinoamericanista" de la obra dariana. Esa médula humana, como precondición para poder fijar su latinoamericanismo, es lo que la revolución sandinista deberá apropiarse popularmente para continuar la línea trazada por su Comandante en Jefe, a quien le interesaba el hombre Darío, el cultor (en términos generales) Darío; y le interesaba en tanto que él (Fonseca) -cultor a su vez- se había dado a la tarea de conectar las líneas que articulaban la historia de Nicaragua, entonces soterradas por el imperialismo. Es un error -esperamos dejar claro a estas alturas- pretender clasificar a Darío como artepurista o como antimperialista y plantear la cuestión en blanco y negro. El hombre-acontecimiento que fue Darío tenía filones diversos que deben ser fijados -sí- para su incorporación racional como elementos conformadores de la nacionalidad y la cultura centroamericanas, pero en toda su riqueza y contradicción. Ese será un aporte valioso de la revolución popular sandinista en el plano de la cultura entendida como práctica social, y su vigor la capacita para semejante tarea.

El punto nodal para articular las líneas entre pasado y futuro de Nicaragua, lo encontró Fonseca en Sandino. El sandinismo triunfante sigue las orientaciones de su jefe al rescatar a Darío de las pálidas fauces del artepurismo, librándolo simultáneamente de las venenosas uñas del sectarismo resentido, hacia su elevamiento justo, humano, popular sandinista y nicaragüense... Y centroamericano.

\section{La destrucción de lo imposible}

Lo imposible ha sido hasta ahora la construcción de la personalidad autónoma de Nuestra América porque su personalidad constituida libremente pasa por la victoria conseguida con sangre sobre el imperialismo. Dos formas de practicar la consecución de ese imposible aparente son Martí y Darío. La revolución cubana y la revolución popular sandinista son dos formas socialmente particulares de lograr tomar las riendas de la práctica colectiva de esa imposibilidad, con lo cual lo imposible se resuelve en su contrario y aún en realidad concreta ya no sólo posible sino de hecho existente.

Darío y Martí nos tienen reunidos aquí con los mismos propósitos. Por nuestra parte hemos tratado de visualizar a Darío desde la óptica de Martí - tal el enfoque pretendido de este trabajo- y eso implica dos cosas: una irrenunciable adhesión martiana y un reconocimiento y admiración hacia Darío. 


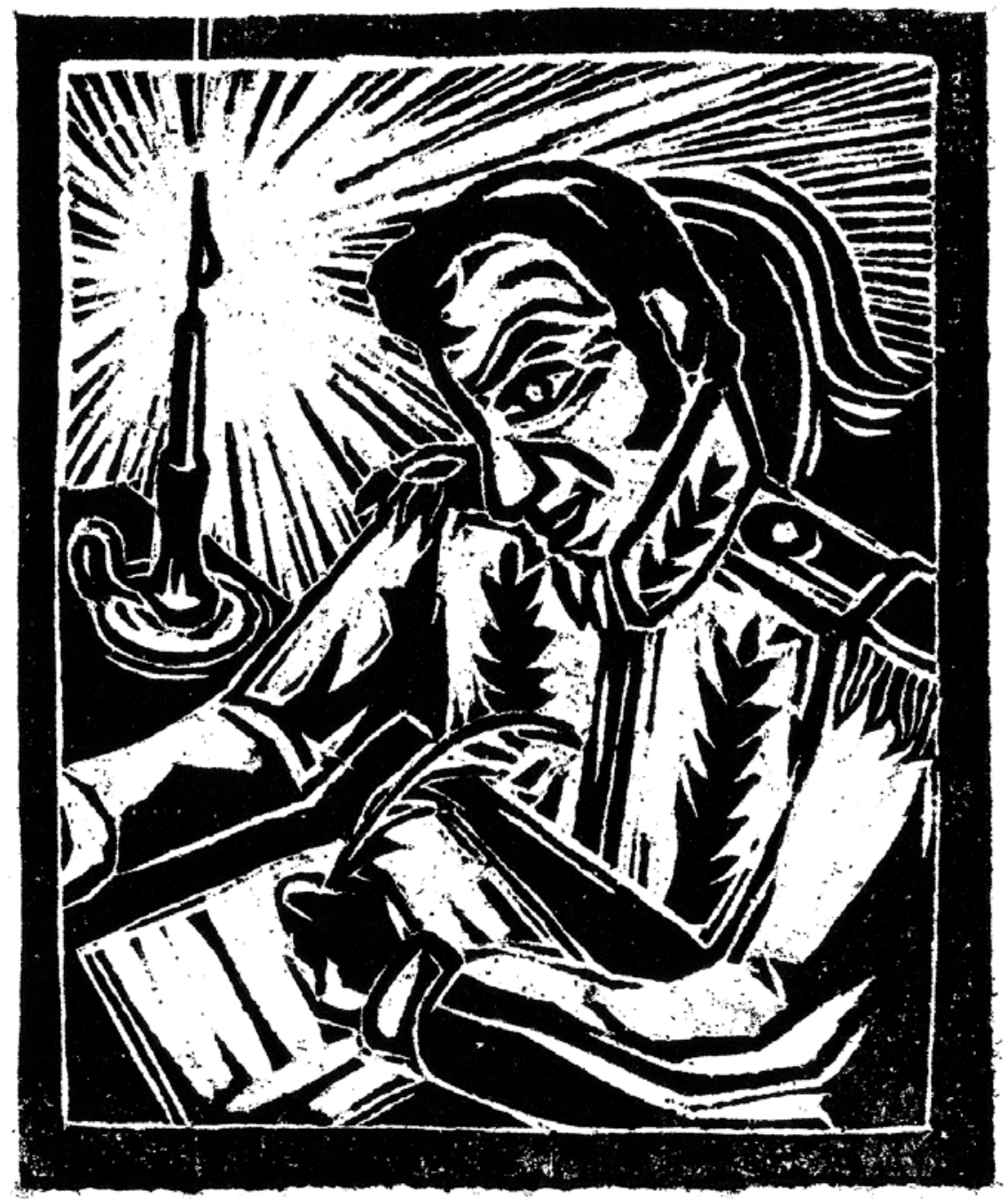

Gabriel Dumani

Libertador Simón Bolivar escribiendo la Carta de Jamaica

Xilografía

$15 \times 10 \mathrm{~cm}$

2017 